\title{
Introduction to the child abuse imaging special issue
}

\author{
Peter J. Strouse $^{1} \cdot$ Arabinda K. Choudhary $^{2} \cdot$ Sabah Servaes $^{3}$
}

Received: 14 October 2020 / Revised: 14 October 2020 / Accepted: 23 November 2020 / Published online: 5 January 2021

(C) Springer-Verlag GmbH Germany, part of Springer Nature 2021

\begin{abstract}
A long time ago, before COVID-19, before the resultant economic upheaval, before the days of social unrest, before the wildfires and the hurricanes, before the contentious election, a meeting occurred in Dallas, TX - the 2020 Child Abuse Imaging Course sponsored by the Society for Pediatric Radiology, developed in conjunction with the American Academy of Pediatrics.

The meeting was an extraordinary collaboration among pediatric radiologists, child abuse pediatricians and a few other experts, coming together to better understand the imaging of child abuse and challenges to the diagnosis. The meeting featured 24 excellent multidisciplinary and multinational speakers, from almost as many institutions and specialties. The diverse roster of speakers spanned various stages of their careers from rising stars to established experts.

Many of the presentations reviewed and updated our understanding of the imaging manifestations of child abuse. For the most part, the imaging findings are not new, but our understanding of their manifestations continually improves through investigation and new paradigms of imaging. Some imaging findings, namely in the orbit and spine, are just now being fully elucidated. Many presentations also concentrated on or featured discussion of the clinical and imaging differential diagnoses of child abuse. As important as it is to make the diagnosis of child abuse, it is
\end{abstract}

Peter J. Strouse

Rad-Ped-Radiol-Journal@med.umich.edu

1 Section of Pediatric Radiology,

C. S. Mott Children's Hospital - Room 3-231,

Department of Radiology, Michigan Medicine,

1540 E. Hospital Drive,

Ann Arbor, MI 48109-4252, USA

2 Department of Radiology,

University of Arkansas Medical Sciences,

Little Rock, AR, USA

3 Division of Pediatric Radiology, Department of Radiology, West Virginia University School of Medicine,

Morgantown, WV, USA equally important to not make the diagnosis. Knowledge of other processes that might mimic child abuse is paramount; this was an important focus of many presentations.

The child abuse pediatricians who spoke provided reviews and updates on many facets of their work and how it melds with the work of the pediatric radiologist. It is important for the pediatric radiologist to be aware of the clinical challenges faced by the child abuse pediatrician and of the considerations and deliberations that go into pursuing a medical workup and imaging for possible child abuse. The work of a child abuse pediatrician is not easy, nor for the faint of heart. Their work is difficult, challenging and, at times, very sad. They interact with families who are challenged, confused, sad and angry, and who need help. Necessarily, child abuse pediatricians are frequently involved in the legal system in civil and criminal proceedings. Their work is relentlessly attacked by some. As exemplified by the presenting child abuse pediatricians in Dallas, they are dedicated, hard-working, diligent and fair in their work. We thank the child abuse pediatricians for the important work they do every day. It is our privilege as pediatric radiologists to support child abuse pediatricians in their difficult task.

The Dallas meeting thus provided a wonderful opportunity for pediatric radiologists to interact with many child abuse pediatricians, both presenters and attendees. This collegiality was apparent during question-and-answer sessions, which led to many engaging and constructive discussions. Exemplifying their dedication, and the importance of pediatric radiology to their work, even more child abuse pediatricians than pediatric radiologists attended the meeting.

As sadly illustrated by the news daily during the coronavirus disease 2019 (COVID-19) pandemic, ignorance and denialism of science is very deleterious. As with the COVID-19 pandemic, the child abuse pandemic has faced challenges by those who deny its existence and by those who fabricate alternative explanations with no scientific validity. In doing so, a few such individuals threaten justice and threaten the health, safety and wellbeing of innocent children 
and their families. Many talks, in addition to discussing legitimate differential diagnoses, allotted some attention to purported or fabricated entities pushed by child abuse denialists. It behooves all involved to be aware of these challenges, to understand the pitfalls created by dubious literature, and to be prepared to address them.

In this special issue of Pediatric Radiology, we are fortunate to have assembled papers from many of the speakers from the Dallas course. This is a trove of timely and practical information on child abuse imaging. Although some of the topics in this issue are imaging-lite, they provide context and knowledge and are important for understanding and furthering the excellent collaboration between pediatric radiologists and child abuse pediatricians.

Although our attention has been drawn to other issues, the COVID-19 pandemic, economic strife, social unrest, and increasingly in an important election year - politics, the pandemic scourge of child abuse carries on and still requires our acute and ongoing attention. Much has been written regarding how the COVID-19 pandemic can lead to an increase in the incidence of child abuse and, conversely, a decrease in the reporting of child abuse. We do not know yet. We do know that child abuse affects children and families of all races, all religions, all socioeconomic groups, all nationalities and all communities. While radiologic images are blinded, appearing only in shades of gray, many aspects of child abuse work are potentially biased by these factors. Going forward, we must allot continued and omnipresent attention to removing bias, to honesty and fairness, and to always working in the best interest of the children and their families.

We thank all of the authors for their important contribution. We know that life has been challenging since we left Dallas and that for some, academic time has been at a premium. Thank you and stay safe!

\section{Compliance with ethical standards}

Conflicts of interest Dr. Choudhary is a medical expert for child abuse cases.

Publisher's note Springer Nature remains neutral with regard to jurisdictional claims in published maps and institutional affiliations. 